\title{
Bioenergy Based Power Sources for Mobile Autonomous Robots
}

\author{
Pavel Gotovtsev ${ }^{1, *}$, Vitaly Vorobiev ${ }^{2}$, Alexander Migalev ${ }^{2}$, Gulfiya Badranova ${ }^{1}$, Kirill Gorin ${ }^{1}$, \\ Andrey Dyakov ${ }^{1}$ and Anatoly Reshetilov ${ }^{1,3}$ \\ 1 Department of Biotechnology and Bioenergy, National Research Centre "Kurchatov Institute", \\ Moscow 123182, Russia; gulfiya.badranova@gmail.com (G.B.); gkvbio@gmail.com (K.G.); \\ berloga.bob@gmail.com (A.D.); anatol@ibpm.pushchino.ru (A.R.) \\ 2 Robotics Laboratory, National Research Centre "Kurchatov Institute", Moscow 123182, Russia; \\ gatus86@mail.ru (V.V.); alexander.migalyov@mail.ru (A.M.) \\ 3 G.K. Skryabin Institute of Biochemistry and Physiology of Microorganisms (IBPM), \\ Russian Academy of Sciences, Pushchino 142290, Russia \\ * Correspondence: gotovtsevpm@gmail.com; Tel.: +7-499-196-95-39; Fax: +7-499-196-17-04
}

Received: 16 November 2017; Accepted: 27 December 2017; Published: 1 January 2018

\begin{abstract}
This paper presents the problem of application of modern developments in the field of bio-energy for the development of autonomous mobile robots' power sources. We carried out analysis of biofuel cells, gasification and pyrolysis of biomass. Nowadays, very few technologies in the bioenergy field are conducted with regards to the demands brought by robotics. At the same time, a number of technologies, such as biofuel cells, have now already come into use as a power supply for experimental autonomous mobile robots. The general directions for research that may help to increase the efficiency of power energy sources described in the article, in case of their use in robotics, are also presented.
\end{abstract}

Keywords: robotics; power supply system; biofuel cells; autonomous mobile robot; bioenergy; bionic systems

\section{Introduction}

Today, robotics is one of the fastest-growing areas of the high-tech industry. During new robotic systems' development, considerable attention is paid to biomimicry, i.e., to attempts to take some natural solutions related to cognitive behavior [1-3] and motions [4,5]. The aim of these efforts is to transfer the most effective principles of various biological systems' and biological objects' organization because many of them are autonomous by their nature, in terms of self-support with essential resources. At the same time, a number of problems in robotics can be solved with the help of autonomous mobile robots that could operate for long periods without replenishing their energy resources (filling tanks with fuel, charging batteries, etc.), including through the use of available surrounding resources.

Mobile robots' autonomy is emerging as a result of growing complexity of behavior algorithms, manipulators and actuators' control, power systems, and robot construction specialization for application environment [6]. Often, this is the result of automation of tasks carried out by a robot under remote control. Power system autonomy arises as a result of this evolution.

However, now, in some power supply systems of autonomous mobile robots, batteries [7] or organic fuel engines (alcohols, gasoline, kerosene) are mainly used [8]. Thus, there are some works devoted to biofuel cells [9-11]. For example, "Gastrobot" described in [9] is a large demonstration robot in which the authors implemented a system of using food as a substrate for microbial biofuel cells' operation. At the same time, biofuel cells is not the only research area that is now being developed into the bioenergy field. There are studies related to various thermal methods of producing energy 
from biomass [12], generation of biofuel for conventional engines $[13,14]$ and the fuel cells with microorganisms, enzymes, metal or metal-oxide nanoparticles as catalysts operating on a biogenic substrate $[15,16]$. Thus, the purpose of this article is to provide a review and analysis of the latest achievements in the bioenergy field, which could find application as potential power sources for autonomous mobile robots. To conduct this work, we have to first consider the types of autonomous mobile robots and their range of application.

\section{Types of Autonomous Mobile Robots}

General strategy in the mobile robotics evolution in fields of agriculture [17], construction activities, mining [18], cleaning [19], patrolling, environment monitoring and investigation [20], and control of technical systems [21] is development of a more autonomous control system, the transition from the remote control to semi- and fully autonomous systems, design of robots structure, and manipulators requiring minimal human-operator's intervention [22], configured for long-term operation without maintenance. From a global concept of autonomy, we should come to a well-known behavior or computational autonomy for which evolution is described by R.A. Brooks in his remarkable paper [23], and energetic autonomy, which is achieved by increasing the energy efficiency of various actuators and control systems, optimization of control algorithms and upgrading of power sources.

Nowadays, robots' power sources based on batteries or combustion engines appear as a key element that limits the extension of autonomous mobile robots applications. The main approaches to overcome this limitation include the following:

1. The development of robots' recharging terminals and robot behavior algorithms that include searching of such terminals and planning its work in a periodic charging operation mode [24,25], finding correct charging time, fuel amount needed for each working cycle, correct behavior strategy for robot depend of power source characteristics and requires theoretical research and modeling [26]. Optimal working cycles with refueling or recharging, searching for energy sources was investigated by D. Mcfarland [27].

2. The use of complex power systems consisting of multiple power sources of different kinds [28,29]. This approach was implemented in Gastrobot [9] and Ecobot robot series [30], where microbial fuel cells (MFC) were used alongside with batteries and ultracapacitors. The distribution of energy between various power sources requires adaptive control and prediction of power consumption. Such energy distribution system based on a neural network model was proposed in [31] for robots with proton exchange membrane (PEM) fuel cell and a bank of ultracapacitors as power sources.

3. With a lack of power for control systems, robot can switch to sleep mode with low power consumption. This approach was implemented in Ecobot robots [30]. The practical implementation of this mechanism can be based on using (along with the main control system) a secondary or back-up control system with reduced power consumption and computation power. As an example of similar architecture, the research robot-hexapod in study [32] can be introduced, although it has been created for other purposes. One computer was used for processing the sensor data and the other for direct servomotors' control;

4. Minimizing of actuators' energy consumption by using more efficient control or by optimizing the design $[33,34]$;

5. The use of heterogeneous systems, for example, a large robot for transporting smaller robots, which are able to solve local tasks but have a lower energy autonomy [35];

6. Effective use of the environment properties. For example, flying amphibian robots' multicopters and planes can be applied for motion in two environments [36]. Energy demanding flight and periodic ground motion can be combined for surface locomotion [37,38]. The combination of the water and surface environments' motion under certain local conditions can extend the range of applications and decrease power consumption. Examples of such solutions are underwater and supermarine legged amphibian robots $[39,40]$. Additionally, in the same environment 
but with different properties, robots can change movement type like the rolling/crawling robot Scorpio developed by Masataka et al. [41] and mimicking spider Cebrenus Rechenburgi movement strategy.

Self-powered robots are especially needed for tasks where application environment hinders the access to permanent power source. It could be marine, underwater and supermarine usage, research of water parameters [42], geodetic situation [24], biological resources [20,43], monitoring and control of engineering structures [6,44]. The same absence of permanent energy source makes aerial robots highly sought after in similar fields: monitoring the Earth's surface and scanning the dangerous environments [38]. Terrestrial robots can be applied in tasks associated with technical control of constructions [21], cleaning [19] and agriculture [17,45]. The main possible application fields of autonomous mobile robots are presented in Figure 1.

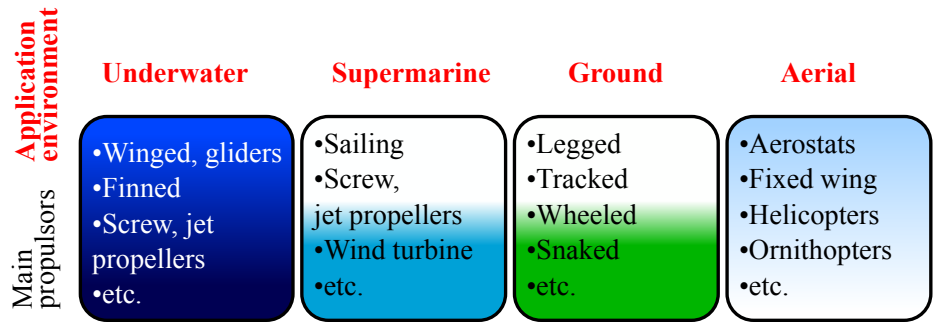

Figure 1. Main autonomous mobile robots' application environments.

Execution of these tasks requires a certain specialization of the robot and its structure considering power consumption. First of all, the type of actuator, optimization of energy consumption for selected environment of application tasks, the robot weight and required maneuverability parameters are important (Figure 1). As an example of designs with a minimum energy consumption, aqueous media sailing robots [46,47] and underwater gliders [39] can be mentioned, which consume energy for motion only when altering the sail shape, wing angle and buoyancy. For an aerial environment, there are aerostats [48] and gliders that use forming thermals for drifting up [49]. For the ground wheeled robots and robots with combined wheel-legged mechanisms, combining legged motion advantages with higher energy efficiency of the wheeled chassis on plain ground are used [50].

Often, for specified tasks, a certain type of motion is required. Mobile robot actuators' technology move towards efficiency upgrading and acquiring of new motion regimes. For example, in the context of ornithopter design, it means abrupt acceleration, deceleration and hovering [51]. Mimicking the flight principles of biological models, such as the dragonfly, ornithopter robots can acquire specific flight regimes such as hovering, soaring, lateral, backward flight and fast forward motion (about $56 \mathrm{~km} / \mathrm{h}$ ) [52]. The design of new piezoelectric motors [35], actuators with integrated control, engines and reducers [4], wing shapes and structures will allow for obtaining the new required motion features. Probably, the application of such robot designs will be associated with development of distributed sensors network in the future [53].

In the aquatic environment, similar approaches tend to implement the designs with different fin shapes. The advantages of fin actuators are noiselessness, possibility of moving backward, for example, by creating a wave motion [54], increased efficiency at low speeds, and high stability while holding attitude [36]. There is a variety of underwater robots' motion strategies that use different fin designs copied from fish, such as modifiable configuration of robot surface [51]. The shape of the fin [55] and propulsion control algorithms today are the subjects of intense theoretical studies [56].

Servomotors of robots moving on a ground surface develop in a similar way of improving energy efficiency through design and control algorithms [33].

Application environment and the range of tasks determine the choice of the actuator type. Often, it specifies requirements for the power system architecture, for example, type of electrical generator, 
fuel cell, and battery. Thus, improvement of autonomous mobile robots' energy efficiency will expand the list of their possible power sources.

Next, let us consider what developments in the field of bioenergy nowadays can potentially find application in the power supply of autonomous mobile robots.

\section{Biofuels for Combustion Engines}

Recent developments in the field of motor biofuels (bioalcohol, biodiesel and bio-kerosene) allow their use in modern combustion engines and gas turbines $[14,57,58]$. However, the use of readymade organic fuel binds robots to their production and distribution points, just as is the case with ordinary equipment and motor transport. An advantage of using biofuel is the possibility of its lean production, especially if the fuel is generated from algae biomass $[13,59]$. For the cultivation of microalgae, only light, water, carbon dioxide and a minimum amount of salts are necessary $[13,60,61]$. Such factories can be located far from major transport routes and can significantly improve mobility and economical efficiency of equipment application through the use of biofuels. Thus, a system with a closed photobioreactor with a capacity of $10 \mathrm{~m}^{3}$ can provide up to from 2 to $5 \mathrm{~kg}$ of biodiesel over 5-7 days, depending on the microalgae strain [13,62]. A standard marine 40-foot High-cube type ISO (International Organization for Standardization)-container theoretically is able to house a photobioreactor with volume of $10-15 \mathrm{~m}^{3}$. Three photobioreactors like this will require one container with equipment for the production of fuel from biomass. This scheme will allow producing from 6 to $15 \mathrm{~kg}$ of biodiesel in situ for 5-7 days [63,64]. Such a stationary source of fuel can be fully automated. In addition, today, mathematical models describing photobioreactors' operation already exist and provide the opportunity to predict their productivity in relation to external factors $\left(\mathrm{CO}_{2}\right.$ concentration, illumination, etc.) [65-67]. In prospect, this technology can be used, for example, in a large slow-moving robotic ship or barge that serves as a fuel source for a number of small autonomous mobile robots as shown in Figure 2.

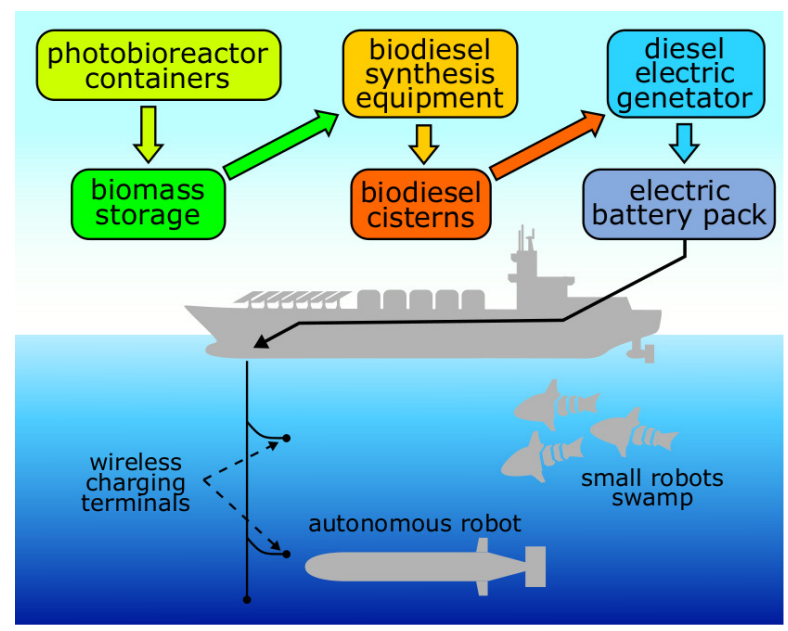

Figure 2. Biofuel synthesis ship example.

\section{Biofuel Cells}

Currently, biofuel cells (BFC) and fuel cells with abiotic catalysts on biogenic substrate are created and studied in many laboratories throughout the world $[68,69]$.

Just as a traditional hydrogen-oxygen fuel cell, BFC includes two electrodes, anode and cathode. One or both of them are bioelectrodes and contain a biocatalyst as enzyme or living microorganisms. Consuming any organic compound (substrate) anode biocatalyst releases electrons that contribute to restoration of the depolarizer (mainly oxygen) at the cathode surface [70]. The total catalytic activity of the biocatalyst immobilized on the electrode surface is the most important factor for achieving high 
output power of BFC [71]. BFC efficacy is evaluated through several parameters. The most common of them is the power density, i.e., the power generated per unit of electrode surface [15,72]. The main objectives for the creation of such devices are the following:

- treatment of contaminated wastewater with organic impurities, such as sewage wastewater, with power production [73];

- development of biofuel or abiotic fuel cells operating on glucose for implantable devices power supply [15] and for wearable devices such as contact lenses [74].

In the first case, the microbial biofuel cells where living microorganisms work as the catalyst are used [16]. In the second case, biofuel cells where particular purified enzyme is functioning as the catalyst are used. In addition, the fuel cells with a metal or metal-oxide catalyst developed for oxidation of glucose also finds its application [75].

It is important to note that the use of the BFC as a power source for autonomous mobile robots requires a battery or capacitors as a secondary power storage. The reason for the battery application is a strong dependence between power generation and amount of consumed substrate [76]. In general, the BFC may be regarded as a promising power source for autonomous mobile robots since it can use various biogenic materials. The large climatic zones can be allocated where substances that might allow BFC to generate electricity theoretically exist.

Next, let us consider each of the three groups of those fuel cells.

\subsection{MFC}

Schematic principles of MFC is presented in Figure 3a. The electron transfer from microorganism to conductive material of electrode can go either directly [77] (shown in Figure 3a as a dir), or by means of mediator-a substance that is cyclically oxidized and reduced in the process of BFC operation [16] (shown in Figure 3a as a med).

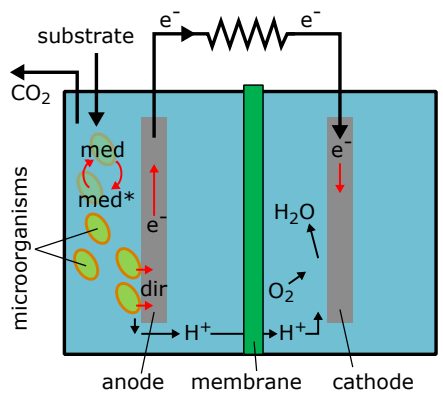

(a)

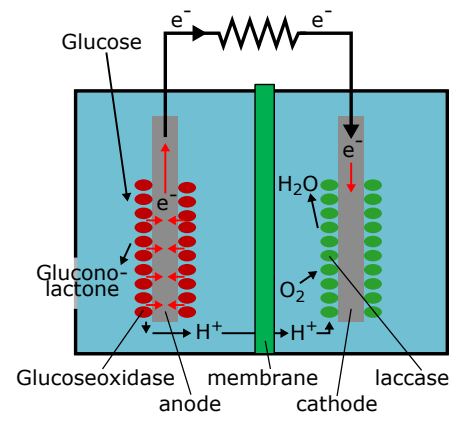

(b)

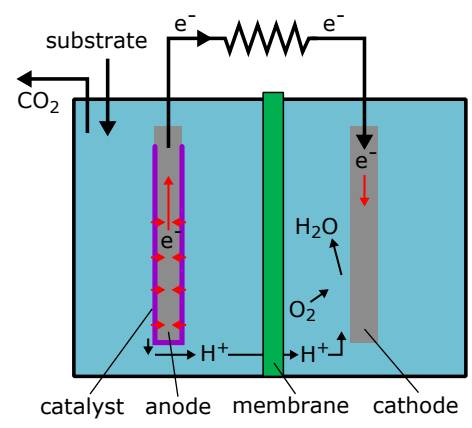

(c)

Figure 3. Schematic principle of fuel cells operation. (a) microbial fuel cell operation. med-chemical mediator for electron transfer from microorganism to anode; dir-direct electron transfer from microorganism to anode; (b) enzyme fuel cell operation; (c) abiotic fuel cell operation. 
In general, MFC can be classed into four categories according to the microorganisms used therein:

1. BFC using single strain of bacteria [68,78];

2. BFC using microbial communities [73];

3. Yeast BFC $[79,80]$;

4. BFC using phototrophic microorganisms [81] microalgae or cyanobacteria [82].

Variants 1, 2 and 3 are capable of generating electricity from organic substrate. The choice of microorganisms for such BFC depends largely on selected substrate. Option 4 also requires light and carbon dioxide from the air. Area of illumination must be large enough due to the low concentration of phototrophic microorganisms in the medium that does not exceed $5 \mathrm{~g} / \mathrm{L}[62,64,83]$. Use of mixed systems where photosynthetic bacteria are presented only in the cathode chamber can partly allow for reducing the illuminated area $[84,85]$. However, in $[84], 7 \mathrm{~mW} / \mathrm{m}^{2}$ of power density was achieved, and, in [86], peak power density was equal to $100 \mathrm{~mW} / \mathrm{m}^{2}$. Thus, the BFC with photosynthetic microorganisms is not suitable as a power supply source for autonomous robots due to its large size.

Next, we will consider only MFC related to groups 1-3. MFC are usually designed to work at high concentrations of organic compounds [72,87]. For example, Reference [73] demonstrates the long-term work on municipal waste water reproduced in the laboratory with power density from 74 to $100 \mathrm{~mW} / \mathrm{m}^{2}$. Furthermore, MFC may operate on different substrates from glucose to oil-products [88], in point of fact using all of them that can be processed by microorganisms or their communities $[78,89,90]$. While developing the MFC, it is important to choose inexpensive materials for electrodes and membranes to create more powerful low-cost devices for industrial applications in prospect [91]. In addition, there are a number of works on creation of MFC working on pure substances, such as glucose [80], xylose [92] or acetate [93,94]. With such substrates, the MFC power has increased significantly. Thus, in [80], a power density of $850 \mathrm{~W}$ per $\mathrm{m}^{3}$ of substrate solution was achieved while using glucose, and, in [93] $2150 \mathrm{~W}$ per $\mathrm{m}^{3}$ while using acetate.

As it was mentioned in the Introduction, one of the most well-known works dedicated to the use of MFC for autonomous robots is a project of creation a "Gastrobots" [9]. The ultimate goal of the project is to create a mobile platform powered by MFC, generating electricity from the maximum possible range of different substrates. The authors have developed a prototype that is driven by MFC generated electricity. MFC was also used to power a miniature robot in work [11]. In this study, the authors have created MFC, which was able to generate power of 10-33 $\mathrm{mW}$ on various substrates that allowed for moving the robot with the curb weight of $780 \mathrm{~g}$ on a smooth surface. A lighter robot with MFC appeared in [10]. Its power supply system includes a MFC and 0.33 Farad capacitor. As the anode catalyst, a consortium of microorganisms from the municipal sewage treatment plants' activated sludge was used. The substrate is organic and bio-organic impurities contained in natural waters. The applicability of this organic matter for MFC is shown in [87]. With a sufficient assay of organic matter, robots can operate in sea and fresh water. Cells in MFC should keep their viability and division capability $[16,95]$. Therefore, a special environment that maintains the viability of microorganisms should be constantly provided in MFC [88]. It is worth noting that, nowadays, several works on the miniaturization of MFC are underway [85]. However, a number of studies indicate that, due to physiological constraints, MFC power density today is already close to the theoretical one $[16,78,95]$. Thus, an important task when creating a compact MFC is to increase the specific surface of the electrodes, which would provide the possibility of contact with a large number of microorganisms.

\subsection{Enzyme BFC}

In enzyme BFC function of catalysts is discharged by enzymes that catalyze the individual reactions or groups of reactions. Schematic principals of such BFC, as an example using glucose, are shown in Figure $3 b$. This BFC is meant for generating electricity by the use of glucose contained in the body fluids of mammals. Both its electrodes are coated with enzymes: glucoseoxidase for glucose breakdown, and laccase for reduction of oxygen to water. Enzyme BFC must provide higher power density than microbial ones, since enzymes can cover the electrode more tightly than cells. 
Thus, enzyme BFC power can reach $18 \mathrm{~mW} / \mathrm{cm}^{2}$ [96]. In addition, the authors of [97] conducted a research of the enzyme BFC developed by them and showed that the power density to handling medium volume can reach $1250 \mathrm{~W} / \mathrm{m}^{3}$. However, enzymes are less stable and, in the case of damage replacement of the electrode being required, while the cells can re-synthesize their enzymes $[15,73,98]$. All BFC running on glucose are designed to generate power at physiological glucose concentrations of 5 to $10 \mathrm{mM}$ [15]. Application of working enzyme BFC electrode system on physiological fluid was demonstrated by placing the electrodes into the cerebrospinal fluid of mouse [99]. Furthermore, in [100], the possibility of enzyme BFC implantation into a mouse has been shown. Power output was $38.7 \mathrm{~mW}$ and implantation period was about one hundred days. In [101], the authors were able to achieve smooth running in a medium with a physiological concentration of glucose during almost one year. These results indicate the possibility of creating enzyme BFC that will continuously operate for a reasonable amount of time.

Another important issue is BFC shutdown. Enzymes should be contained in a certain environment to hold their conformation. Therefore, to shutdown BFC, it is necessary to replace the medium to organic-free buffered solution, or cut off the substrate supply and let BFC shut down after utilization of all organic compounds. Furthermore, as for power requirements, it is desirable to ensure functionability for the entire service life of the robot, up to several years.

For both microbial and enzyme BFC, one of the most important problems is the selection of the electrode material [15]. The material should be nontoxic, easily immobilize enzymes and at the same time have a high electroconductivity. For implantable microdimensional BFC, cost of material is less important than for large powerful BFC, which require a considerable amount of material for its creation. Thus, carbon nanotubes [96,102] and gold [99] widely discussed today can make a large robot BFC quite expensive.

\subsection{Fuel Cells with Abiotic Catalyst for Use with Biological Fluids}

This type of fuel cell uses metal nanoparticles, metal oxides, and more complex compound on their basis as catalysts. Schematic principals of such a fuel cell operation are shown in Figure 3c. The effectiveness of such specific metal and metal-oxide catalysts is limited with a low temperature supposed for these fuel cells' operation. The physiological use of such devices sets the temperature limits up to $37^{\circ} \mathrm{C}$ [75]. Thus, the power density in these cells reaches $180 \mathrm{~mW} / \mathrm{cm}^{2}$ [75]. Currently, the problem of such a low power can be solved with the use of expensive nano-structured materials and the optimization of the fuel cell design. In [103], the authors used cobalt/platinum and cobalt phthalocyanine/multiwall carbon nanotubes systems as an anode and a cathode, respectively. A working medium containing $0.5 \mathrm{M} \mathrm{KOH}$ and $0.5 \mathrm{M}$ of glucose was pumped through the fuel cell at a rate of $5 \mathrm{~mL} / \mathrm{min}$. Under such conditions, it was possible to achieve power density of $2.3 \mathrm{~mW} / \mathrm{cm}^{2}$. Thus, it was shown that, at high substrate concentrations, fuel cells with abiotic catalyst could reach power comparable with enzyme BFC and be quite acceptable to supply small devices.

It should also be noted that catalysts of this sort are more stable and their use allows shutdown of the fuel cell just by blocking substrate supply.

Table 1 summarizes the main properties of different types of BFC and FC on biotic substrates.

It is necessary to mention that calculation of power density with respect to electrode surface area is complicated due to several factors including the need of surface measurements in microscale (close to microbial cell surface) and cell population dynamics (population size changes during MFC operation). This means that the increasing of power density is a subject for further research and development.

Let us consider possible applications of described BFC types in environments where the use of autonomous mobile robots is planned. Fuel cell selection depends on a number of factors, which are determined by the application environment and specifics of the task performed by the autonomous mobile robot. Among these factors, we would like to specifically mention the availability of raw materials for different types of fuel cells in different environments. In Figure 4, a schematic diagram with possible BFC applications in different environments versus the biomass availability is shown. 
In the column "ground", biomass-deficient desert and Polar Regions were not considered. The use of biofuel cells for flying autonomous mobile robots can be discussed only in the case of specialized tasks, allowing for a long time to be on the ground or water. The data above also demonstrate that the BFC power rise comes with a rise of supplied substrate purity demands, which obviously leads to higher power consumption for its pretreatment.

Table 1. The properties of different types of BFC (biofuel cells) and fuel cells with abiotic catalyst on biotic substrates.

\begin{tabular}{cccc}
\hline Index & Enzyme BFC & MFC & FC with Abiotic Catalyst \\
\hline $\begin{array}{c}\text { Power density } \\
\text { achieved by now }\end{array}$ & Up to $18 \mathrm{~mW} / \mathrm{cm}^{2}[96]$ & Up to $0.19 \mathrm{~mW} / \mathrm{cm}^{2}[16,78]$ & Up to $2.3 \mathrm{~mW} / \mathrm{cm}^{2}[103]$ \\
\hline Used substrates & $\begin{array}{c}\text { The narrow substrate specificity. } \\
\text { Most of the works are focused on } \\
\text { aqueous solutions of glucose, } \\
\text { less often - methanol in small } \\
\text { concentrations. }\end{array}$ & $\begin{array}{c}\text { The broad substrate specificity. } \\
\text { The use of microbial communities } \\
\text { significantly extends the range of } \\
\text { natural substrates. }\end{array}$ & $\begin{array}{c}\text { Potentially broad substrate } \\
\text { specificity. However, today, we } \\
\text { don't have enough data on } \\
\text { promising catalysts for this type } \\
\text { of FC for various substrates. }\end{array}$ \\
\hline $\begin{array}{c}\text { Substrate } \\
\text { pretreatment }\end{array}$ & Required & $\begin{array}{c}\text { Minimal, and not necessary in } \\
\text { some cases. However, it can give } \\
\text { possibility to increase power. }\end{array}$ & $\begin{array}{c}\text { Required, at least, for } \\
\text { transformation of substrate to } \\
\text { liquid homogenous state. }\end{array}$ \\
\hline $\begin{array}{c}\text { Time of stable } \\
\text { operation }\end{array}$ & $\begin{array}{c}\text { implantation into mouse }[15] \text { Up } \\
\text { to } 1 \text { year in a medium with } \\
\text { a physiological concentration of } \\
\text { glucose [101] }\end{array}$ & $\begin{array}{c}\text { Depends on structural } \\
\text { components lifetime in case of } \\
\text { microorganisms survival }\end{array}$ & $\begin{array}{c}\text { Depends on lifetime of } \\
\text { structural components }\end{array}$ \\
\hline $\begin{array}{c}\text { Operation } \\
\text { temperature }\end{array}$ & Not above $37^{\circ} \mathrm{C}$ & $\begin{array}{c}\text { Not above } 37^{\circ} \mathrm{C} \text { up to } 60-70^{\circ} \mathrm{C} \text { if } \\
\text { thermophilic microorganism is } \\
\text { applied [104] }\end{array}$ & $\begin{array}{c}\text { Limited with thermostability of } \\
\text { the materials used }\end{array}$ \\
\hline
\end{tabular}

Abbreviations: BFC - biofuel cell; MFC - microbal fuel cell; FC - fuel cell.

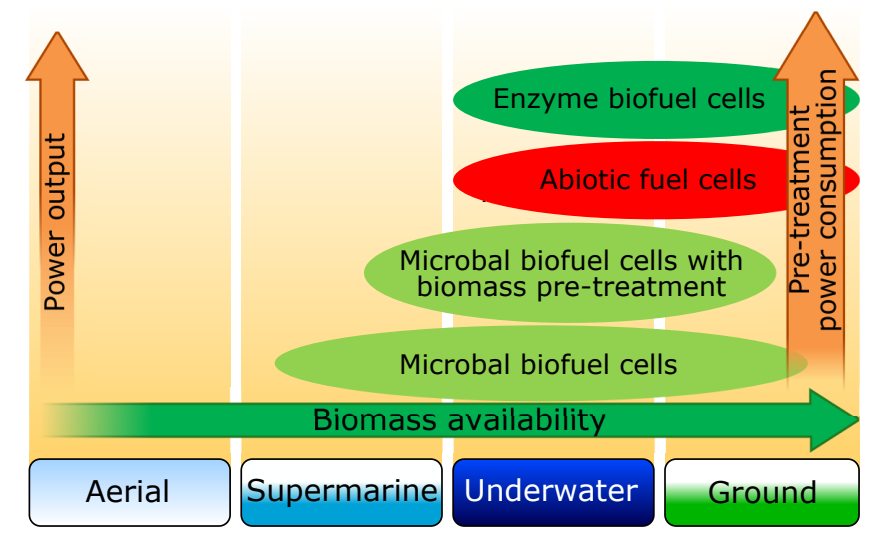

Figure 4. Schematic diagram with possible applications of biofuel and abiotic cells for autonomous mobile robots in different environments.

Due to the small number of examples of BFC application for robots, it is difficult to carry out in-depth analysis of power-to-weight ratio for each type of BFC, but some tendencies can be noted now. The substrate is fed into the BFC working cells in liquid state and the cells themselves occupy the major part of the device capacity (about 75-90\%). Therefore, the BFC specific weight will converge to the substrate density, which may be in the range of about $1-1.4 \mathrm{~kg} / \mathrm{dm}^{3}$, depending on the chemical composition and pretreatment. In the case of marine and underwater robots, this parameter is less critical, since BFC in them may operate on the principle of pumping seawater through the cells. At the same time, for ground robots, this parameter largely determines the weight of the chassis. As for power, it was shown above that today values up to $2000 \mathrm{~W} / \mathrm{m}^{3}$ are already achievable [80]. 
Thus, it is already possible to create a BFC with power-to-weight ratio is about $2 \mathrm{~W} / \mathrm{kg}$. However, this parameter ignores a possible substrate pretreatment, which on one hand increases the weight and internal power consumption of the engine, and on the other hand increases the concentration of energy-intensive substances in the substrate. The growth of the concentration of these substances leads to $B F C$ power rise.

On the basis of information presented in this article, we can try to highlight some options for power generation improvement in the case of autonomous mobile robots' application for power supply.

\section{Enzyme BFC}

1. Development of substrate pretreatment system with such individual needs that can make the total net generation exceed MFC working with the same substrate without pretreatment; in addition, it must conform to the weight and size requirements of the robot that it is designed for. Possible designs of such systems will be reviewed in the section of the article dedicated to the biomass fermentation;

2. Ensurement of long-term stability of enzymes on the electrode, especially when BFC is deactivated. The problem solving may require chambers with buffer solutions have a negative impact on the robot weight;

3. Search for inexpensive highly conductive materials with high-surface area for electrode, as currently the maximum power is achieved by using expensive and rare materials;

4. Exploration of the possibility of using thermophilic microorganisms' enzymes, that will allow for raising the temperature to about $50-60{ }^{\circ} \mathrm{C}$ and thereby increase the rate of reaction.

\section{MFC}

1. Search of new electrode materials is also essential, but it should be noted that BFC power output is limited both by physiology of microorganisms and their electron transport systems [95]. The value presented in Table 1 is considered today as closest to the theoretically achievable $[16,95]$. Therefore, a high-surface area should become the main aspect in the search and development of new materials.

2. In case of application of microbial communities (for example $[10,11]$ ), the further research can be focused on increasing of communities' efficiency via development of artificial communities or maintaining its stability by using selected conditions of communities' preliminary cultivation.

3. Using the thermophilic microorganisms or their communities can also theoretically increase the power of MFC, but this issue requires further study.

4. Development of low cost electrode and membrane materials $[68,105]$.

\section{FC with Abiotic Catalyst}

1. As in the case of enzyme BFC, it is necessary to develop a substrate pretreatment system with such individual needs that can make the total net generation exceed MFC working with feedstock; in addition it must conform to the weight and size requirements of the robot which it is designed for. However, FC with abiotic catalyst will be less substrate specific than the enzyme one. In theory, it will allow for creating a simpler and less energy-intensive system.

2. Today, the most common catalysts are platinum group metals. This is why searching for less expensive catalysts is very important.

3. This type of FC is much less limited by temperature. Thus, for technical applications, the temperature and pressure of the substrate can be raised and thus the reaction rate and the FC power will increase correspondently.

For All Types of FC:

1. The crucial role in the efficiency and operation stability of specified FC types play the supply of substrate to the catalyst and removal of reaction products [106,107]. As it was shown in [31], optimization of the cell design and its hydraulic control potentially can offer some power increase and lead to a reduction of its weight and size characteristics; 
2. Microbial and enzyme BFC do not completely decompose large organic compounds to carbon dioxide and water $[15,108]$. It was demonstrated in [31] that the cascade system with successive use of substrate by several FCs can be a good option to increase the power of energy sources in general.

As can be seen from the data presented, FC types we reviewed are very interesting sources of energy for autonomous robots depend of environment, operation conditions and robots' tasks. Their development potentialities are still very far from being exhausted. Research on the design optimization and operating conditions may allow for expanding significantly the range of applications for a variety of autonomous mobile robots.

\section{Plant Biomass Fermentation}

For mobile autonomous robots, the most available kind of raw material overland is plant biomass. The use of higher plants would exclude the energy consumption for exploration and production of animal biomass. Fuel generation from plant biomass today can be performed either by enzymatic or thermal processing [109]. In the case of MFC application, plant biomass pretreatment is required because it is difficult to somehow consume lignocellulosic biomass for use in MFC microorganisms [110,111]. In this section, we will examine some aspects of fermentation and analyze the possibility of its application for mobile robots.

The conventional scheme of plant biomass fermentation to bioalcohol includes three stages [112,113]: disintegration and often hot water pretreatment, saccharification and further fermentation until obtaining the alcohol. The process of saccharification is quite long and can take up to several days [113]. Fermentation proceeds faster, but it is also a question of several tens of hours. To increase the speed of these processes, several studies now on thermostable enzymes' usage [114-116] and pretreatment stage effectivization [112] are under way. A very promising solution is the use of ionic liquids for biomass pretreatment [117-119]. Ionic liquids are composed mostly of ions. As a general, these are molten salts, including organic, with a melting temperature of about $20-25^{\circ} \mathrm{C}$ [117]. They are capable of dissolving cellulose and that simplifies subsequent enzymatic reactions [118]. Thus, current research is focused on process efficiency increasing, in particular on conversion and speedup. This trend is relevant in the case of autonomous robots because the saccharification process may act as a pretreatment of plant biomass for its further use in more effective enzyme or abiotic fuel cells.

\section{The Pyrolysis and Gasification of Biomass}

Thermal processing of the lignin-containing biomass today is one of the fastest growing areas in bioenergetics $[120,121]$. Thermal processing of such biomass with production of gaseous and/or liquid fuels pertains to pyrolysis and gasification. An advantage of thermal processing is the high speed of running processes in comparison with biological methods such as fermentation.

Gasification generally means the combustion process with a lack of oxidizer in comparison with the stoichiometry [121]. The product of gasification is syngas composed of carbon monoxide and hydrogen in a lesser degree, and methane more rarely [122]. In addition, the solid phase consisting of ash and soot is formed. Currently, there are no engineering constraints for syngas use as the main fuel in gas turbines and gas reciprocating engines [123].

Pyrolysis is a process of thermal decomposition in oxidant absence or its minimal presence. While pyrolysis the pyrolysis gas is produced, and depending on the type of fuel, pyrolysis oil and/or pyrolysis coal can also be formed [120,124]. As in the case of gasification, ash is produced as a waste.

Schematic principals of the power source in the case of pyrolysis or gasification use (by the example of gasification) are shown in Figure 5a. The harvested biomass is pretreated by disintegration, may be dried and then is fed into the gasifier.The syngas from the gasifier is burned in the engine (for example, in a gas turbine or a gas engine) that powers the generator rotor. To stabilize the modes of power generation and consumption, battery installation is required. 


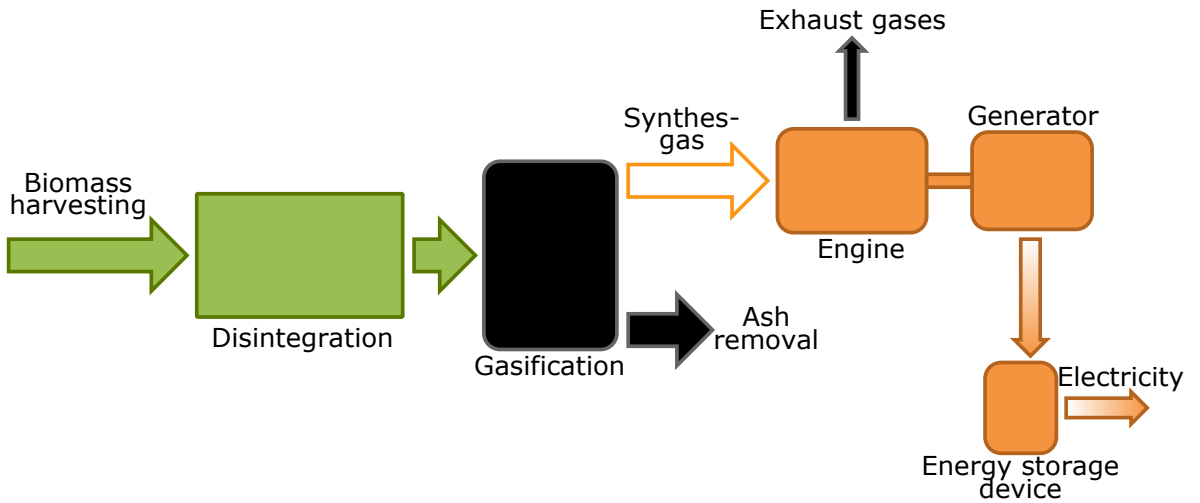

(a)

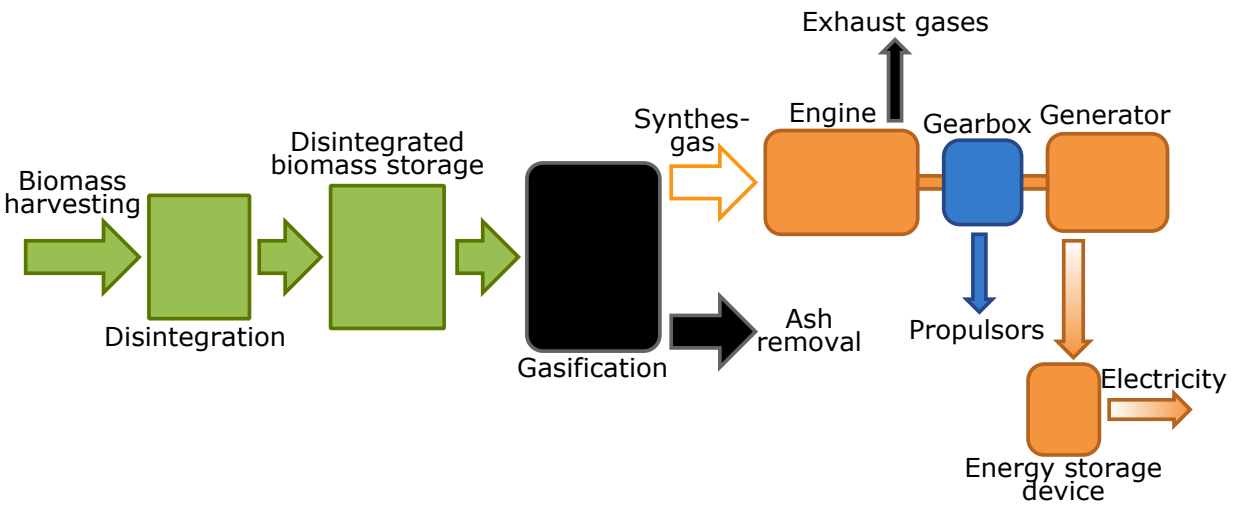

(b)

Figure 5. Schematic principals of the propulsion system. (a) system with application of gasification without biomass storage; (b) system with application of gasification with biomass storage and gearbox.

For robots with a wheeled chassis, an option with the biomass accumulation before gasifier in a special container instead of batteries can be suggested. In this case, the main engine load is provided with a robot propulsion control. Schematic principals of such a device are shown in Figure $5 \mathrm{~b}$. In terms of applications for autonomous robots, both processes have similar advantages and disadvantages. The advantages are:

1. Both technologies are well proven and now it is possible to create a system using a gasifier with a loaded weight about $10-30 \mathrm{~kg}$;

2. Possibility of using almost all sufficiently dried higher plants.

However, there are a number of disadvantages:

1. The complex and multi-component system, with plenty of power transmissions, especially in biomass disintegration part;

2. Initial biomass humidity limitations [121]. Wet biomass requires drying and, as a result, additional systems with extra energy consumption are needed, which finally increase robot weight;

3. This system produces waste in ash and exhaust gases.

Selection of this power generation system is promising in the case of certain types of biomass usage, such as grass or leaves and sawdust, but this limits its application only for ground autonomous mobile robots. Then, it is possible to optimize and simplify both the disintegration system and the gasifier itself, which can result in weight savings. 


\section{Discussion and Conclusions}

As is shown in review, bioenergetic approaches now just start to be applied in power supply of autonomous mobile robots. The main advantage of such approaches is a consumption of external resources, such as biomass and organic compounds, which are present in the environment. A motor biofuel generation scheme described in this article may allow to synthesize it in the future in any place for autonomous robots with internal combustion engine needs.

Technical solutions presented in the paper, yet are the first steps towards the use of bioenergetics for autonomous mobile robots' power supply. It is important to note that there are many opportunities to improve the efficiency of the proposed solutions. This applies especially for BFC, with a large number of directions for future research that we showed above. However, today, BFC already may be applied at least as an additional source of energy for partially autonomous robots, which constantly charges the robot batteries and thus increases its run-time. This solution is very attractive for marine and underwater robots, since there are already several successful examples of MFC use in marine environments $[10,87]$. Depending on the executed tasks, for such types of robots, "sleep mode" proposed by D. McFarland [27] and applied in Gastrobot [9] and Ecobot robot series [30] can be used, when the robot is inactive and charges its battery using BFC. In general, expanding the range of applications of marine and underwater autonomous mobile robots can be accompanied with a more active use of MFC.

We can especially focus on abiotic FC using biomass. As it is seen from the survey, there are still no works on the adaptation of such FC for robots power supply or on creation of a substrate pretreatment systems for them. However, the ability of such fuel cells to use a wide range of organic compounds and their possible applicability at higher temperatures can result in use of this type of devices for ground robots because of their potentially high power density.

Thermal methods today are already investigated well enough to create robots at some fairly narrow form of plant biomass. Due to the raw materials' humidity restrictions, obviously, this decision is applied for ground robots only. However, the biomass availability and problems associated with the generation of waste in ash and exhaust gases should be taken into account.

New technologies lead to new challenges. Furthermore, in the case of usage of external resources for autonomous mobile robots, there appears a problem of designing of control systems that ensure efficient biomass search. This problem is directly related to the energy efficiency of the chosen solution, since energy consumption at the time when the robot collects suitable biomass, can be attributed to "own energy needs" of power system. Marine and underwater robots can be an exception because their MFC cells may be supplied with biomass due to the natural water flow or robot movement.

In summary, we can say that as well as bio-inspired technologies finding applications in tasks associated with the motion, cognitive behavior, sensor coating (artificial leather) [1,4,125], they may find a use in the modern autonomous mobile robots' power supply.

Acknowledgments: We thank the management and the staff of the National Research Centre "Kurchatov Institute" for their support in research.

Author Contributions: P.G. and A.M. wrote the paper. All authors participated in data collection. P.G. and A.M. provided data analysis.

Conflicts of Interest: The authors declare no conflict of interest.

\section{Abbreviations}

The following abbreviations are used in this manuscript:

PEM proton exchange membrane

MFC microbal fuel cell

BFC biofuel cell

FC fuel cell

ISO International Organization for Standardization 


\section{References}

1. Asada, M.; Hosoda, K.; Kuniyoshi, Y.; Ishiguro, H.; Inui, T.; Yoshikawa, Y.; Ogino, M.; Yoshida, C. Cognitive developmental robotics: A survey. IEEE Trans. Auton. Ment. Dev. 2009, 1, 12-34.

2. Jiang, M.; Zhang, L. Big Data Analytics as a Service for Affective Humanoid Service Robots. Procedia Comput. Sci. 2015, 53, 141-148.

3. Asada, M.; MacDorman, K.F.; Ishiguro, H.; Kuniyoshi, Y. Cognitive developmental robotics as a new paradigm for the design of humanoid robots. Robot. Auton. Syst. 2001, 37, 185-193.

4. Nguyen, Q.V.; Park, H.C.; Goo, N.S.; Byun, D. Characteristics of a beetle's free flight and a flapping-wing system that mimics beetle flight. J. Bionic Eng. 2010, 7, 77-86.

5. Rahman, M.M.; Sugimori, S.; Miki, H.; Yamamoto, R.; Sanada, Y.; Toda, Y. Braking performance of a biomimetic squid-like underwater robot. J. Bionic Eng. 2013, 10, 265-273.

6. Gancet, J.; Urbina, D.; Letier, P.; Ilzokvitz, M.; Weiss, P.; Gauch, F.; Antonelli, G.; Indiveri, G.; Casalino, G.; Birk, A.; et al. DexROV: Dexterous undersea inspection and maintenance in presence of communication latencies. IFAC-PapersOnLine 2015, 48, 218-223.

7. Puskaric, M.; Kukushkin, I.; Haskovic, D. Power supply concept for mobile robots in bionic assembly system. Procedia Eng. 2014, 69, 861-870.

8. Kaisare, N.S.; Vlachos, D.G. A review on microcombustion: Fundamentals, devices and applications. Prog. Energy Combust. Sci. 2012, 38, 321-359.

9. Wilkinson, S. "Gastrobots"-Benefits and challenges of microbial fuel cells in foodpowered robot applications. Auton. Robots 2000, 9, 99-111.

10. Philamore, H.; Rossiter, J.; Stinchcombe, A.; Ieropoulos, I. Row-bot: An energetically autonomous artificial water boatman. In Proceedings of the 2015 IEEE/RSJ International Conference on Intelligent Robots and Systems (IROS), Hamburg, Germany, 28 September-2 October 2015; pp. 3888-3893.

11. Melhuish, C.; Ieropoulos, I.; Greenman, J.; Horsfield, I. Energetically autonomous robots: Food for thought. Auton. Robots 2006, 21, 187-198.

12. Ju, Y.; Maruta, K. Microscale combustion: Technology development and fundamental research. Prog. Energy Combust. Sci. 2011, 37, 669-715.

13. Lee, O.K.; Seong, D.H.; Lee, C.G.; Lee, E.Y. Sustainable production of liquid biofuels from renewable microalgae biomass. J. Ind. Eng. Chem. 2015, 29, 24-31.

14. Blakey, S.; Rye, L.; Wilson, C.W. Aviation gas turbine alternative fuels: A review. Proc. Combust. Inst. 2011, 33, 2863-2885.

15. Cosnier, S.; Goff, A.L.; Holzinger, M. Towards glucose biofuel cells implanted in human body for powering artificial organs: Review. Electrochem. Commun. 2014, 38, 19-23.

16. Rosenbaum, M.A.; Franks, A.E. Microbial catalysis in bioelectrochemical technologies: Status quo, challenges and perspectives. Appl. Microbiol. Biotechnol. 2014, 98, 509-518.

17. Sørensen, C.; Jørgensen, R.; Maagaard, J.; Bertelsen, K.; Dalgaard, L.; Norremark, M. Conceptual and user-centric design guidelines for a plant nursing robot. Biosyst. Eng. 2010, 105, 119-129.

18. Shukla, A.; Karki, H. Application of robotics in onshore oil and gas industry-A review Part I. Robot. Auton. Syst. 2016, 75, 490-507.

19. Rivas, E.; Mitobe, K. Development of the intake system for the SnowEater robot. Mechatronics 2015, $28,27-34$.

20. Nishida, Y.; Ura, T.; Hamatsu, T.; Nagahashi, K.; Inaba, S.; Nakatani, T. Resource investigation for Kichiji rockfish by autonomous underwater vehicle in Kitami-Yamato bank off Northern Japan. ROBOMECH J. 2014, 1, 2.

21. López, J.; Pérez, D.; Paz, E.; Santana, A. WatchBot: A building maintenance and surveillance system based on autonomous robots. Robot. Auton. Syst. 2013, 61, 1559-1571.

22. Molfino, R.M.; Razzoli, R.P.; Zoppi, M. Autonomous drilling robot for landslide monitoring and consolidation. Autom. Constr. 2008, 17, 111-121.

23. Brooks, R.A. From earwigs to humans. Robot. Auton. Syst. 1997, 20, 291-304.

24. Han, J.; Asada, A.; Ura, T.; Yamauchi, Y.; Yagita, Y.; Maki, T. Noncontact power supply for seafloor geodetic observing robot system. J. Mar. Sci. Technol. 2007, 12, 183-189.

25. Mintchev, S.; Ranzani, R.; Fabiani, F.; Stefanini, C. Towards docking for small scale underwater robots. Auton. Robots 2015, 38, 283-299. 
26. Wawerla, J.; Vaughan, R.T. Optimal robot recharging strategies for time discounted labour. In Artificial Life XI; The MIT Press: Cambridge, MA, USA, 2008; pp. 670-677.

27. McFarland, D.; Spier, E. Basic cycles, utility and opportunism in self-sufficient robots. Robot. Auton. Syst. 1997, 20, 179-190.

28. Joh, H.I.; Ha, T.J.; Hwang, S.Y.; Kim, J.H.; Chae, S.H.; Cho, J.H.; Prabhuram, J.; Kim, S.K.; Lim, T.H.; Cho, B.K.; et al. A direct methanol fuel cell system to power a humanoid robot. J. Power Sources 2010, 195, 293-298.

29. Kumar, R.; Baghel, O.; Sidar, S.K.; Sen, P.K.; Bohidar, S.K. Energy supply system in robotics machines. Int. J. Innov. Res. Sci. Technol. 2014, 1, 219-226.

30. Ieropoulos, I.; Greenman, J.; Melhuish, C.; Horsfield, I. EcoBot-III: A robot with guts. In Artificial Life X: Proceedings of the Twelfth International Conference on the Synthesis and Simulation of Living Systems; The MIT Press: Cambridge, MA, USA, 2010; pp. 733-740.

31. Chen, Q.; Long, R.; Quan, S.; Zhang, L. Nonlinear recurrent neural network predictive control for energy distribution of a fuel cell powered robot. Sci. World J. 2014, 2014, 1-9.

32. Galloway, K.C.; Haynes, G.C.; Ilhan, B.D.; Johnson, A.M.; Knopf, R.; Lynch, G.A.; Plotnick, B.N.; White, M.; Koditschek, D.E. X-RHex: A Highly Mobile Hexapedal Robot for Sensorimotor Tasks; Technical Report; Department of Electrical and Systems Engineering, University of Pennsylvania: Philadelphia, PA, USA, 2010.

33. Gonzalez-Rodriguez, A.G.; Gonzalez-Rodriguez, A.; Castillo-Garcia, F. Improving the energy efficiency and speed of walking robots. Mechatronics 2014, 24, 476-488.

34. Anderson, J.M.; Chhabra, N.K. Maneuvering and stability performance of a robotic tuna. Integr. Comp. Biol. 2002, 42, 118-126.

35. Guo, S.; Mao, S.; Shi, L.; Li, M. Development of an amphibious mother spherical robot used as the carrier for underwater microrobots. In Proceedings of the 2012 ICME International Conference on Complex Medical Engineering (CME), Kobe, Japan, 1-4 July 2012, pp. 758-762.

36. Xiang, X.; Hu, T.; Zhou, H.; Ma, Z. Evaluating the fin-ray trajectory tracking of bio-inspired robotic undulating fins via an experimental-numerical approach. Int. J. Adv. Robot. Syst. 2014, 11, 98. [CrossRef]

37. Peterson, K.; Fearing, R.S. Experimental dynamics of wing assisted running for a bipedal ornithopter. In Proceedings of the 2011 IEEE/RSJ International Conference on Intelligent Robots and Systems, San Francisco, CA, USA, 25-30 September 2011; pp. 5080-5086.

38. Daler, L.; Mintchev, S.; Stefanini, C.; Floreano, D. A bioinspired multi-modal flying and walking robot. Bioinspir. Biomim. 2015, 10, 016005.

39. Zhang, S.; Yu, J.; Zhang, A.; Zhang, F. Spiraling motion of underwater gliders: Modeling, analysis, and experimental results. Ocean Eng. 2013, 60, 1-13.

40. Li, M.; Guo, S.; Hirata, H.; Ishihara, H. Design and performance evaluation of an amphibious spherical robot. Robot. Auton. Syst. 2015, 64, 21-34.

41. Masataka, F.; Mohan, R.E.; Tan, N.; Nakamura, A.; Pathmakumar, T. Terrain perception in a shape shifting rolling-Crawling robot. Robotics 2016, 5, 19.

42. Gomáriz, S.; Masmitjà, I.; González, J.; Masmitjà, G.; Prat, J. GUANAY-II: An autonomous underwater vehicle for vertical/horizontal sampling. J. Mar. Sci. Technol. 2015, 20, 81-93.

43. Zhao, Y.; Fukuhara, M.; Usami, T.; Takada, Y. Performance of very small robotic fish equipped with CMOS camera. Robotics 2015, 4, 421-434.

44. Schjlberg, I.; Utne, I. Towards autonomy in ROV operations. IFAC-PapersOnLine 2015, 48, 183-188.

45. Grimstad, L.; From, P.J. The Thorvald II agricultural robotic system. Robotics 2017, 6, 24.

46. Pêtrès, C.; Romero-Ramirez, M.A.; Plumet, F. A potential field approach for reactive navigation of autonomous sailboats. Robot. Auton. Syst. 2012, 60, 1520-1527.

47. Santos, D.; Silva Junior, A.G.; Negreiros, A.; Vilas Boas, J.; Alvarez, J.; Araujo, A.; Aroca, R.V.; Goncalves, L.M.G. Design and implementation of a control system for a sailboat robot. Robotics 2016, 5, 5.

48. Jurdak, R.; Elfes, A.; Kusy, B.; Tews, A.; Hu, W.; Hernandez, E.; Kottege, N.; Sikka, P. Autonomous surveillance for biosecurity. Trends Biotechnol. 2015, 33, 201-207.

49. Ákos, Z.; Nagy, M.; Leven, S.; Vicsek, T. Thermal soaring flight of birds and unmanned aerial vehicles. Bioinspir. Biomim. 2010, 5, 045003.

50. Jin, B.; Chen, C.; Li, W. Power consumption optimization for a hexapod walking robot. J. Intell. Robot. Syst. 2013, 71, 195-209. 
51. Liu, J.; Hu, H. Biological inspiration: From carangiform fish to multi-joint robotic fish. J. Bionic Eng. 2010, 7, 35-48.

52. Dileo, C.; Deng, X. Design of and experiments on a dragonfly-inspired robot. Adv. Robot. 2009, 23, $1003-1021$. [CrossRef]

53. Liu, H.; Nakata, T.; Gao, N.; Maeda, M.; Aono, H.; Shyy, W. Micro air vehicle-motivated computational biomechanics in bio-flights: Aerodynamics, flight dynamics and maneuvering stability. Acta Mech. Sin. 2010, 26, 863-879.

54. Zhang, Y.; He, J.; Low, K. Parametric study of an underwater finned propulsor inspired by bluespotted ray. J. Bionic Eng. 2012, 9, 166-176.

55. Shao, J.; Wang, L.; Yu, J. Development of an artificial fish-like robot and its application in cooperative transportation. Control Eng. Pract. 2008, 16, 569-584.

56. Wang, T.; Wen, L.; Liang, J.; Wu, G. Fuzzy vorticity control of a biomimetic robotic fish using a flapping lunate tail. J. Bionic Eng. 2010, 7, 56-65.

57. Yuzbasheva, E.Y.; Gotovtsev, P.M.; Mostova, E.B.; Perkovskaya, N.I.; Lomonosova, M.A.; Butylin, V.V.; Sineokii, S.P.; Vasilov, R.G. Biodiesel production via enzymatic catalysis. Appl. Biochem. Microbiol. 2014, 50, 737-749.

58. Chiaramonti, D.; Prussi, M.; Buffi, M.; Tacconi, D. Sustainable bio kerosene: Process routes and industrial demonstration activities in aviation biofuels. Appl. Energy 2014, 136, 767-774.

59. Bennion, E.P.; Ginosar, D.M.; Moses, J.; Agblevor, F.; Quinn, J.C. Lifecycle assessment of microalgae to biofuel: Comparison of thermochemical processing pathways. Appl. Energy 2015, 154, 1062-1071.

60. Zhang, Y.H.P. Production of biofuels and biochemicals by in vitro synthetic biosystems: Opportunities and challenges. Biotechnol. Adv. 2015, 33, 1467-1483.

61. Lee, Y.K. Microalgal mass culture systems and methods: Their limitation and potential. J. Appl. Phycol. 2001, 13, 307-315.

62. Vandamme, D.; Foubert, I.; Muylaert, K. Flocculation as a low-cost method for harvesting microalgae for bulk biomass production. Trends Biotechnol. 2013, 31, 233-239.

63. Gorin, K.V.; Sergeeva, Y.E.; Butylin, V.V.; Komova, A.V.; Pojidaev, V.M.; Badranova, G.U.; Shapovalova, A.A.; Konova, I.A.; Gotovtsev, P.M. Methods coagulation/flocculation and flocculation with ballast agent for effective harvesting of microalgae. Bioresour. Technol. 2015, 193, 178-184.

64. Uduman, N.; Qi, Y.; Danquah, M.K.; Forde, G.M.; Hoadley, A. Dewatering of microalgal cultures: A major bottleneck to algae-based fuels. J. Renew. Sustain. Energy 2010, 2, 012701. [CrossRef]

65. Pruvost, J.; Gouic, B.L.; Lepine, O.; Legrand, J.; Borgne, F.L. Microalgae culture in building-integrated photobioreactors: Biomass production modelling and energetic analysis. Chem. Eng. J. 2016, 284, 850-861.

66. De Andrade, G.; Berenguel, M.; Guzman, J.; Pagano, D.; Acien, F. Optimization of biomass production in outdoor tubular photobioreactors. J. Process Control 2016, 37, 58-69.

67. Zhao, B.; Su, Y.; Zhang, Y.; Cui, G. Carbon dioxide fixation and biomass production from combustion flue gas using energy microalgae. Energy 2015, 89, 347-357.

68. Shukla, A.K.; Suresh, P.; Berchmans, S.; Rajendran, A. Biological fuel cells and their applications. Curr. Sci. 2004, 87, 455-468.

69. Rousseau, R.; Rimboud, M.; Delia, M.L.; Bergel, A.; Basseguy, R. Electrochemical characterization of microbial bioanodes formed on a collector/electrode system in a highly saline electrolyte. Bioelectrochemistry 2015, 106, 97-104.

70. Reshetilov, A.N. Biosensors and biofuel cells: Research focused on practical application (Review). Appl. Biochem. Microbiol. 2015, 51, 264-269.

71. Alferov, S.V.; Minaicheva, P.R.; Arlyapov, V.A.; Asulyan, L.D.; Alferov, V.A.; Ponamoreva, O.N.; Reshetilov, A.N. Bioanode for a microbial fuel cell based on Gluconobacter oxydans immobilized into a polymer matrix. Appl. Biochem. Microbiol. 2014, 50, 637-643.

72. Bretschger, O.; Osterstock, J.B.; Pinchak, W.E.; Ishii, S.; Nelson, K.E. Microbial fuel cells and microbial ecology: Applications in ruminant health and production research. Microb. Ecol. 2010, 59, 415-427.

73. Commault, A.S.; Lear, G.; Weld, R.J. Maintenance of Geobacter-dominated biofilms in microbial fuel cells treating synthetic wastewater. Bioelectrochemistry 2015, 106, 150-158.

74. Falk, M.; Andoralov, V.; Silow, M.; Toscano, M.D.; Shleev, S. Miniature biofuel cell as a potential power source for glucose-sensing contact lenses. Anal. Chem. 2013, 85, 6342-6348. [CrossRef] 
75. Rapoport, B.I.; Kedzierski, J.T.; Sarpeshkar, R. A glucose fuel cell for implantable brain-machine interfaces. PLOS ONE 2012, 7, e38436.

76. Reshetilov, A.N.; Kitova, A.E.; Dyakov, A.V.; Gotovtsev, P.M.; Vasilov, R.G.; Gutorov, M.A. Converter-based accumulation of electric energy generated by microbial biofuel cell. IOP Conf. Ser. Earth Environ. Sci. 2017, 52, 012010.

77. Korth, B.; Rosa, L.F.; Harnisch, F.; Picioreanu, C. A framework for modeling electroactive microbial biofilms performing direct electron transfer. Bioelectrochemistry 2015, 106, 194-206.

78. Du, Z.; Li, H.; Gu, T. A state of the art review on microbial fuel cells: A promising technology for wastewater treatment and bioenergy. Biotechnol. Adv. 2007, 25, 464-482.

79. Hubenova, Y.; Mitov, M. Extracellular electron transfer in yeast-based biofuel cells: A review. Bioelectrochemistry 2015, 106, 177-185.

80. Kaneshiro, H.; Takano, K.; Takada, Y.; Wakisaka, T.; Tachibana, T.; Azuma, M. A milliliter-scale yeast-based fuel cell with high performance. Biochem. Eng. J. 2014, 83, 90-96.

81. Strik, D.P.; Timmers, R.A.; Helder, M.; Steinbusch, K.J.; Hamelers, H.V.; Buisman, C.J. Microbial solar cells: Applying photosynthetic and electrochemically active organisms. Trends Biotechnol. 2011, 29, 41-49.

82. Bradley, R.W.; Bombelli, P.; Rowden, S.J.; Howe, C.J. Biological photovoltaics: Intra- and extra-cellular electron transport by cyanobacteria. Biochem. Soc. Trans. 2012, 40, 1302-1307.

83. Kumar, R.D.; Manikandavelu, D.; Kasirajan, K.G. Fixation of carbon dioxide and oxygen production by photosynthetic simulations in indoor environs. J. Algal Biomass Util. 2010, 1, 84-88.

84. Gajda, I.; Greenman, J.; Melhuish, C.; Ieropoulos, I. Photosynthetic cathodes for Microbial Fuel Cells. Int. J. Hydrogen Energy 2013, 38, 11559-11564.

85. Choi, S. Microscale microbial fuel cells: Advances and challenges. Biosens. Bioelectron. 2015, 69, 8-25.

86. Bombelli, P.; Müller, T.; Herling, T.W.; Howe, C.J.; Knowles, T.P.J. A high power-density, mediator-free, microfluidic biophotovoltaic device for cyanobacterial cells. Adv. Energy Mater. 2015, 5, 1401299.

87. Lowy, D.A.; Tender, L.M.; Zeikus, J.G.; Park, D.H.; Lovley, D.R. Harvesting energy from the marine sediment-water interface II. Biosens. Bioelectron. 2006, 21, 2058-2063.

88. Pant, D.; Bogaert, G.V.; Diels, L.; Vanbroekhoven, K. A review of the substrates used in microbial fuel cells (MFCs) for sustainable energy production. Bioresour. Technol. 2010, 101, 1533-1543.

89. Velasquez-Orta, S.B.; Curtis, T.P.; Logan, B.E. Energy from algae using microbial fuel cells. Biotechnol. Bioeng. 2009, 103, 1068-1076.

90. Zhang, T.; Gannon, S.M.; Nevin, K.P.; Franks, A.E.; Lovley, D.R. Stimulating the anaerobic degradation of aromatic hydrocarbons in contaminated sediments by providing an electrode as the electron acceptor. Environ. Microbiol. 2010, 12, 1011-1020.

91. Kircheva, N.; Outin, J.; Perrier, G.; Ramousse, J.; Merlin, G.; Lyautey, E. Bio-electrochemical characterization of air-cathode microbial fuel cells with microporous polyethylene/silica membrane as separator. Bioelectrochemistry 2015, 106, 115-124.

92. Catal, T.; Li, K.; Bermek, H.; Liu, H. Electricity production from twelve monosaccharides using microbial fuel cells. J. Power Sources 2008, 175, 196-200.

93. Nevin, K.P.; Richter, H.; Covalla, S.F.; Johnson, J.P.; Woodard, T.L.; Orloff, A.L.; Jia, H.; Zhang, M.; Lovley, D.R. Power output and columbic efficiencies from biofilms of Geobacter sulfurreducens comparable to mixed community microbial fuel cells. Environ. Microbiol. 2008, 10, 2505-2514.

94. Choi, S.; Lee, H.S.; Yang, Y.; Parameswaran, P.; Torres, C.I.; Rittmann, B.E.; Chae, J. A $\mu$ L-scale micromachined microbial fuel cell having high power density. Lab Chip 2011, 11, 1110-1117.

95. Logan, B.E. Exoelectrogenic bacteria that power microbial fuel cells. Nat. Rev. Microbiol. 2009, 7, 375-381.

96. Kanwal, A.; Wang, S.C.; Ying, Y.; Cohen, R.; Lakshmanan, S.; Patlolla, A.; Iqbal, Z.; Thomas, G.A.; Farrow, R.C. Substantial power density from a discrete nano-scalable biofuel cell. Electrochem. Commun. 2014, 39, 37-40.

97. Sakai, H.; Nakagawa, T.; Tokita, Y.; Hatazawa, T.; Ikeda, T.; Tsujimura, S.; Kano, K. A high-power glucose/oxygen biofuel cell operating under quiescent conditions. Energy Environ. Sci. 2009, 2, 133-138.

98. Wu, X.; Wang, X.; Lu, W. Genome-scale reconstruction of a metabolic network for Gluconobacter oxydans 621H. Biosystems 2014, 117, 10-14.

99. Andoralov, V.; Falk, M.; Suyatin, D.B.; Granmo, M.; Sotres, J.; Ludwig, R.; Popov, V.O.; Schouenborg, J.; Blum, Z.; Shleev, S. Biofuel cell based on microscale nanostructured electrodes with inductive coupling to rat brain neurons. Sci. Rep. 2013, 3, 3270. 
100. Zebda, A.; Cosnier, S.; Alcaraz, J.P.; Holzinger, M.; Le Goff, A.; Gondran, C.; Boucher, F.; Giroud, F.; Gorgy, K.; Lamraoui, H.; et al. Single glucose biofuel cells implanted in rats power electronic devices. Sci. Rep. 2013, 3, 1516.

101. Reuillard, B.; Abreu, C.; Lalaoui, N.; Goff, A.L.; Holzinger, M.; Ondel, O.; Buret, F.; Cosnier, S. One-year stability for a glucose/oxygen biofuel cell combined with $\mathrm{pH}$ reactivation of the laccase/carbon nanotube biocathode. Bioelectrochemistry 2015, 106, 73-76.

102. Milton, R.D.; Giroud, F.; Thumser, A.E.; Minteer, S.D.; Slade, R.C. Glucose oxidase progressively lowers bilirubin oxidase bioelectrocatalytic cathode performance in single-compartment glucose/oxygen biological fuel cells. Electrochim. Acta 2014, 140, 59-64.

103. Elouarzaki, K.; Haddad, R.; Holzinger, M.; Goff, A.L.; Thery, J.; Cosnier, S. MWCNT-supported phthalocyanine cobalt as air-breathing cathodic catalyst in glucose/O2 fuel cells. J. Power Sources 2014, 255, 24-28.

104. Elleuche, S.; Schäfers, C.; Blank, S.; Schröder, C.; Antranikian, G. Exploration of extremophiles for high temperature biotechnological processes. Curr. Opin. Microbiol. 2015, 25, 113-119.

105. Reshetilov, A.N.; Plekhanova, J.V.; Tarasov, S.E.; Bykov, A.G.; Gutorov, M.A.; Alferov, S.V.; Tenchurin, T.K.; Chvalun, S.N.; Orekhov, A.S.; Shepelev, A.D.; et al. Evaluation properties of bioelectrodes based on carbon superfine materials containing model microorganisms Gluconobacter. Nanotechnol. Russia 2017, 12, 107-115.

106. Do, T.; Varničić, M.; Hanke-Rauschenbach, R.; Vidaković-Koch, T.; Sundmacher, K. Mathematical modeling of a porous enzymatic electrode with direct electron transfer mechanism. Electrochim. Acta 2014, 137, 616-626.

107. Do, T.; Varničić, M.; Flassig, R.; Vidaković-Koch, T.; Sundmacher, K. Dynamic and steady state 1-D model of mediated electron transfer in a porous enzymatic electrode. Bioelectrochemistry 2015, 106, 3-13.

108. Fan, S.; Hou, C.; Liang, B.; Feng, R.; Liu, A. Microbial surface displayed enzymes based biofuel cell utilizing degradation products of lignocellulosic biomass for direct electrical energy. Bioresour. Technol. 2015, 192, 821-825.

109. Nanda, S.; Azargohar, R.; Dalai, A.K.; Kozinski, J.A. An assessment on the sustainability of lignocellulosic biomass for biorefining. Renew. Sustain. Energy Rev. 2015, 50, 925-941.

110. Garba, N.; Sa'adu, L.; Dambatta, M. An overview of the substrates used in microbial fuel cells. Greener J. Biochem. Biotechnol. 2017, 4, 7-26.

111. Pandey, P.; Shinde, V.N.; Deopurkar, R.L.; Kale, S.P.; Patil, S.A.; Pant, D. Recent advances in the use of different substrates in microbial fuel cells toward wastewater treatment and simultaneous energy recovery. Appl. Energy 2016, 168, 706-723.

112. Khare, S.K.; Pandey, A.; Larroche, C. Current perspectives in enzymatic saccharification of lignocellulosic biomass. Biochem. Eng. J. 2015, 102, 38-44.

113. Farinas, C.S. Developments in solid-state fermentation for the production of biomass-degrading enzymes for the bioenergy sector. Renew. Sustain. Energy Rev. 2015, 52, 179-188.

114. Maurelli, L.; Giovane, A.; Esposito, A.; Moracci, M.; Fiume, I.; Rossi, M.; Morana, A. Evidence that the xylanase activity from Sulfolobus solfataricus $\mathrm{O} \alpha$ is encoded by the endoglucanase precursor gene (sso1354) and characterization of the associated cellulase activity. Extremophiles 2008, 12, 689-700.

115. Cannio, R.; Di Prizito, N.; Rossi, M.; Morana, A. A xylan-degrading strain of Sulfolobus solfataricus: Isolation and characterization of the xylanase activity. Extremophiles 2004, 8, 117-124.

116. Bronnenmeier, K.; Kern, A.; Liebl, W.; Staudenbauer, W.L. Purification of thermotoga maritima enzymes for the degradation of cellulosic materials. Appl. Environ. Microbiol. 1995, 61, 1399-1407.

117. Fedorov, M.V.; Kornyshev, A.A. Ionic liquids at electrified interfaces. Chem. Rev. 2014, 114, 2978-3036, doi:10.1021/cr400374x.

118. Socha, A.M.; Parthasarathi, R.; Shi, J.; Pattathil, S.; Whyte, D.; Bergeron, M.; George, A.; Tran, K.; Stavila, V.; Venkatachalam, S.; et al. Efficient biomass pretreatment using ionic liquids derived from lignin and hemicellulose. Proc. Natl. Acad. Sci. USA 2014, 111, E3587-E3595.

119. Zhao, H. Methods for stabilizing and activating enzymes in ionic liquids-A review. J. Chem. Technol. Biotechnol. 2010, 85, 891-907.

120. Li, B.; Ou, L.; Dang, Q.; Meyer, P.; Jones, S.; Brown, R.; Wright, M. Techno-economic and uncertainty analysis of in situ and ex situ fast pyrolysis for biofuel production. Bioresour. Technol. 2015, 196, 49-56. 
121. Pérez, J.F.; Benjumea, P.N.; Melgar, A. Sensitivity analysis of a biomass gasification model in fixed bed downdraft reactors: Effect of model and process parameters on reaction front. Biomass Bioenergy 2015, 83, 403-421.

122. Patra, T.K.; Sheth, P.N. Biomass gasification models for downdraft gasifier: A state-of-the-art review. Renew. Sustain. Energy Rev. 2015, 50, 583-593.

123. Abdoulmoumine, N.; Adhikari, S.; Kulkarni, A.; Chattanathan, S. A review on biomass gasification syngas cleanup. Appl. Energy 2015, 155, 294-307.

124. Shen, D.; Jin, W.; Hu, J.; Xiao, R.; Luo, K. An overview on fast pyrolysis of the main constituents in lignocellulosic biomass to valued-added chemicals: Structures, pathways and interactions. Renew. Sustain. Energy Rev. 2015, 51, 761-774.

125. Bauer, S.; Bauer-Gogonea, S.; Graz, I.; Kaltenbrunner, M.; Keplinger, C.; Schwodiauer, R. 25th anniversary article: A soft future: from robots and sensor skin to energy harvesters. Adv. Mater. 2014, 26, 149-162.

(c) 2018 by the authors. Licensee MDPI, Basel, Switzerland. This article is an open access article distributed under the terms and conditions of the Creative Commons Attribution (CC BY) license (http:/ / creativecommons.org/licenses/by/4.0/). 